\title{
Paul E. Lovejoy Prize
}

Brill and the editorial team of the Journal of Global Slavery are pleased to provide an annual prize of $€_{5}$ oo for excellence and originality in a major work (defined as a monograph or feature documentary) on any theme related to global slavery published in a calendar year.

The Paul E. Lovejoy Prize is named after the esteemed slavery scholar and distinguished professor of African Studies and African Diasporic Studies at York University in Canada. The author of more than thirty books and a hundred articles, Lovejoy pioneered new approaches to the historical study of slavery in West Africa and its diasporic communities, and played a critical role in revealing the interconnectedness between various African, Atlantic and Islamic systems of enslavement in the early modern and modern periods. He was the founding Director of the Harriet Tubman Institute for Research on the Global Migrations of African Peoples and a former board member of the International Scientific Committee of the UnEsco Slave Routes Project "Resistance, Liberty, Heritage" from 1996 to 2012.

Submissions for the Lovejoy Prize must be in English (in the case of documentaries they may be subtitled in English) and accompanied by a cover letter. Digital versions of monographs (e-books or pdfs of final proofs) are preferable to hard copies, in order to make them more accessible to committee members. Please send an email to jgslovejoyprize@gmail.com for specific instructions. The Journal of Global Slavery appoints a jury consisting of 3-4 members, who are all active and prominent scholars in their fields, for a one-year period (renewable to a max of three years). The jury is headed by the editor in chief of the Journal. 